\title{
Maria en la Teologia: ¿̇Reflexiones elaboradas en despachos o en fronteras?
}

\author{
Maria in the Theology: \\ Reflections prepared in offices or in borders?
}

María del Pilar Silveira

\section{Resumen}

En el presente artículo, haré un sintético recorrido destacando los principales lineamientos teológicos sobre la mariología desde el Vaticano II y el magisterio papal con aportes relevantes de la reflexión teológica europea. Luego continuaré refiriéndome a las Conferencias Episcopales latinoamericanas y su aporte teológico. Haré una breve referencia al magisterio del Papa Francisco que por ser el primer papa latinoamericano, contiene elementos de ambos aportes. Culmino reflexionando en las investigaciones actuales sobre la mariología y la fe popular, aseverando que el permanente intercambio entre ambos saberes, ayuda a avanzar en la comprensión teológica de la fe.

Palabras claves: María. Mariología. Mariología popular. Iglesia. Magisterio.

\section{Abstract}

In the present article, I will do a synthetic trip "highlighting" the main "mariological lines of theology" from the Vatican II and papal teaching with relevant contributions from European theological reflection. I will then be referencing the Latin-American conferences of bishops and their theological contribution. Next, I will briefly reference the magisterium of Pope Francis whom being the first Latin-American pope, integrates elements of both 
contributions. I conclude reflecting on the current research on Mariology and the popular faith, affirming that the permanent exchange between both knowledges, helps advance the theological comprehension of our faith.

Keywords: Mary. Mariology. Popular Mariology. Church. Magisterium.

\section{Introducción}

No se conformen con una teología de despacho. Que el lugar de sus reflexiones sean las fronteras. Y no caigan en la tentación de pintarlas, perfumarlas, acomodarlas un poco y domesticarlas. También los buenos teólogos, como los buenos pastores, huelen a pueblo y a calle y, con su reflexión, derraman ungüento y vino en las heridas de los hombres. ${ }^{1}$

Partiendo de la descripción que hace el Papa Francisco sobre la teología, es oportuno acercarnos a la mariología magisterial y a la fe popular mariana para conocer ese rico intercambio que surge cuando el creyente acoge con fe la doctrina cristiana a través de la predicación y la pone por obra en gestos, acciones y pensamientos. Sabemos que las declaraciones y definiciones del magisterio sobre la Virgen María destacando su importancia en la historia de la salvación y el lugar que ocupa en la Iglesia, son un referente universal para nuestra fe que se incultura en cada continente, país, región. Por lo cual las siguientes preguntas guiarán este artículo: ¿qué lugar ocupa María en la teología? La reflexión sobre la experiencia vital mariana de los devotos, ¿se elabora en los despachos, es decir en base a análisis teológicos sobre las afirmaciones magisteriales y teológicas, sin contacto con la fe popular?

\section{Mariología y los lineamientos del Magisterio Pontificio.}

Los Concilios ecuménicos que son la suprema expresión del magisterio eclesial, junto con el magisterio papal, contienen declaraciones sobre la Virgen

\footnotetext{
${ }^{1}$ FRANCISCO. "Carta al Cardenal Mario Aurelio Poli, Arzobispo de Buenos Aires y Gran Canciller de la Universidad Católica Argentina (UCA) en ocasión de los 100 años de la Facultad de Teología". Aciprensa, Roma, 3 de marzo de 2015. Disponible en: $<$ https://www. aciprensa.com/noticias/no-se-conformen-con-una-teologia-de-despacho-pide-papa-franciscoa-la-uca-13143/>. Consulta el 5 de abril 2017.
} 
entre las que se destacan los cuatro dogmas marianos. ${ }^{2}$ Las orientaciones magisteriales son una guía para el desarrollo de la mariología y de teología sobre la revelación de Dios. En este sentido nos interesa el enfoque del Concilio Vaticano II porque orienta la reflexión teológica actual teniendo en cuenta que contiene la riqueza del pensamiento mariano hasta mediados $\mathrm{XX}{ }^{3}$ Destaco como antecedente inmediato que en 1960 el tratado de mariología buscaba insertarse en la eclesiología y en la cristología como síntesis de datos adquiridos en una reflexión global. Las corrientes de renovación de la mariología iban por la vía histórico salvífica, estética y experiencial, visión que inspira y asume el Concilio Vaticano II. Entre sus Documentos no encontramos uno específico sobre mariología, a pesar de que fue materia de debate entre los padres conciliares, que buscaban un nuevo enfoque influenciados por las corrientes innovadoras que aconsejaban retornar a las fuentes. Vale mencionar el movimiento litúrgico, bíblico, kerygmático, el renacimiento patrístico que insiste en la eclesiología. Movimientos basados en la fe de los fieles.

La referencia a la Virgen María aparece en el capítulo VIII del Documento Lumen Gentium (LG): "La Santísima Virgen María, Madre de Dios, en el Misterio de Cristo y de la Iglesia". ${ }^{4}$ El título hace referencia a tres tratados: mariología, cristología y eclesiología. Se ubica a la Madre de Dios dentro del Documento sobre la Iglesia, marcando un hito en la teología al invitar a descubrir el principio mariano que opera en la vida eclesial a través de la historia.

Pablo VI clausuró el concilio el 8 de diciembre de 1965, proclamando a María "Madre de la Iglesia" y le encomendó con vistas al futuro la fecunda aplicación de las decisiones conciliares. Su magisterio contribuyó en la renovación de la devoción mariana dando importancia a las fuentes bíblicas,

\footnotetext{
${ }^{2}$ Los dogmas marianos: virginidad perpetua, maternidad divina, inmaculada concepción y de la gloriosa asunción al cielo.

${ }^{3}$ Las publicaciones que contribuyeron al desarrollo de la mariología del siglo XX fueron: las apariciones de Fátima en 1917, las sociedades mariológicas internacionales en 1931, la definición dogmática de la asunción en 1950, el año mariano en 1954 y los congresos mariológicos y marianos internacionales. La producción fue muy fructuosa pues hasta el año 1950, se publicaba un tratado por año. Por ejemplo: en 1900 los tratados de mariología de J. B. Terrien, A. M. Lépicier, E. Campana; en 1930 los tratados que adoptan el nombre de mariología de G. Alastruey, J. Keuppens, B. E Merkelbach. Después de la Segunda Guerra mundial aparecen publicaciones de Roschini, y tratados mariológicos de D. Bertetto, P. Sträter, R. Laurentin, J. A. de Aldama, J. B. Carol, M. Schmaus.

${ }^{4}$ VATICANO II. "Lumen Gentium". Numeral 52 al 69. In: Documentos Conciliares. Buenos Aires: Ediciones Paulinas, 1988, pp. 80-90.
} 
la dimensión trinitaria, cristológica, eclesiológica y antropológica en su Exhortación Apostólica Marialis Cultus (MC) ${ }^{5}$ (1974).

Es preciso mencionar el impulso que el Documento Dei Verbum (DV) ${ }^{6}$ en el n. 12 propició a la mariología, al abrir nuevas posibilidades de conocer a la Virgen María interpretando la Sagrada Escritura por medio de los géneros literarios, histórico, profético, poético y otras maneras de expresarse siguiendo el espíritu del hagiógrafo.

Juan Pablo II en la Exhortación Apostólica Redemptoris Mater (RM) ${ }^{7}$ (1987) hace una relación entre María y la Iglesia en base a LG 8, contribuyendo a la apertura ecuménica en Occidente. ${ }^{8}$ En la Exhortación Apostólica Mulieris Dignitatem (MD) (1988), numeral 27b, demuestra que el perfil mariano de la iglesia es fundamental y característico al compararlo con el perfil apostólico petrino.

El Concilio Vaticano II, confirmando la enseñanza de toda la tradición, ha recordado que en la jerarquía de la santidad precisamente la "mujer", María de Nazaret, es "figura" de la Iglesia. Ella "precede" a todos en el camino de la santidad; en su persona la "Iglesia ha alcanzado ya la perfección con la que existe inmaculada y sin mancha" (cf. Ef 5, 27). En este sentido se puede decir que la Iglesia es, a la vez, "mariana" y "apostólico-petrina". 9

Benedicto XVI en la apertura del XXIII Congreso Mariológico Mariano Internacional, realizado en Roma del 4 al 9 de septiembre 2012 sobre: "La mariología a partir del Concilio Vaticano II. Recepción, balance y perspectivas", recordó el contexto mariano del Concilio Vaticano II que "se abrió el día 11 de octubre, en el mismo día que el Concilio de Éfeso (431) había proclamado a María “Theotokos", Madre de Dios. Agregó que el Vaticano II para la mariología "constituye el horizonte hermenéutico esencial para cada

\footnotetext{
${ }^{5}$ PABLO VI. Exhortación Apostólica Marialis Cultus. Roma: Tipografía Vaticana, 1974.

${ }^{6}$ VATICANO II. “Dei Verbum”. N. 12. In: Documentos Conciliares, pp. 97-109.

7 JUAN PABLO II. Exhortación Apostólica Redemptoris Mater. Bogotá: Ediciones Paulinas, 1988.

${ }^{8}$ Cfr. LEAHY, B. El principio mariano en la eclesiología de Hans Urs Von Balthasar. Madrid: Ciudad Nueva, 2002, p. 38, cita a Von Balthasar que interpreta a Juan Pablo II.

9 JUAN PABLO II. "Carta apostólica Mulieris Dignitatem". Vatican, Roma, N. 27b, 30 de septiembre de 1988. Disponible en: https://w2.vatican.va/content/john-paul-ii/es/apost letters/1988/documents/hf_jp-ii_apl_19880815_mulieris-dignitatem.html. Consulta el 13 de abril de 2017.
} 
reflexión posterior, sea de carácter teológico" como espiritual y pastoral; y "representa, también, un precioso punto de equilibrio, siempre necesario, entre la racionalidad teológica y la afectividad creyente". ${ }^{10}$

\section{Algunas reflexiones teológicas europeas}

Entre las aplicaciones post conciliares, sucedió que en la medida que se fue describiendo el misterio de la Iglesia, se fue avanzando en el misterio de la Madre de Dios ya que las características de la Iglesia se atribuyen a María. Así su condición femenina se asemeja a la iglesia en su carácter simbólico de novia virgen, esposa, madre fecunda, que engendra, da a luz y ayuda a crecer a los hijos e hijas. Su rostro misericordioso refleja la bondad y la ternura del Padre hacia la humanidad. Es oportuno destacar que no es una novedad la descripción de la Iglesia con un rostro femenino, sino que es parte de su tradición ${ }^{11}$ desde el inicio de la fe en la primitiva comunidad cristiana.

Los escritos del teólogo Von Balthasar sobre el principio mariano de la Iglesia ${ }^{12}$ contribuyeron en la comprensión teológica propuesta por Lumen

\footnotetext{
${ }^{10}$ BENEDICTO XVI. "Discurso de apertura XXIII Congreso Mariológico Mariano Internacional". Gaudiumpress, Roma, 10 de octubre de 2012. Disponible en: < http://es.gaudiumpress. org/content/40129-El-Concilio-Vaticano-II-representa-en-la-mariologia-el-punto-de-equilibrio-entre-la-racionalidad-teologica-y-la-afectividad-creyente--observa-el-Papa $>$. Consultado 13 de abril 2017.

${ }^{11} \mathrm{Cfr}$. Entre los escritos que recogen la descripción de la iglesia con rostro femenino en la iglesia primitiva se destacan: PLUMPE, J. Mater Ecclesia. Washington: Catholic University of America Press, 1943, DELAHAYE, K. Ecclesia Mater. Paris: Les Éditions du Cerf, 1964; DE LUBAC, H. Meditación sobre la Iglesia. Pamplona: Desclée de Brouwer, 1959.

12 María es miembro de la Iglesia, está presente desde antes de su fundación "oficial”, como afirman los Santos Padres (Justino, Irineo, Ambrosio, Orígenes, Metodio). Para Orígenes y Metodio, María es el "alma de la Iglesia" anima ecclesiastica. Orígenes. Cant. Hom., I: 10. Von Balthasar desarrolla este concepto en su obra: VON BALTHASAR, H. U. Teoldramática II. Madrid: Encuentro, 1992, pp. 284-285. Ver: ORIGENES. Homilías sobre el cantar de los cantares. Introducción, traducción y notas de Samuel Fernández Eyzaguirre. Madrid: Ciudad Nueva, 2000, pp. 19 -29. Para San Justino en su obra Dialogo con el judio Trifón y para San Irineo, el concepto de María Virgen y Madre se relaciona con la Iglesia Virgen y Madre. Se hace un paralelismo entre Eva-María valorando el sí de María por el cual dio a luz al que es la Cabeza de la Iglesia. Irineo. Adversus haereses, IV, 33, 4.11, citado por VON BALTHASAR, H. U. El complejo antirromano. Madrid: BAC, 1981, pp. 201-202. San Ambrosio afirmaba que todos los creyentes podían llegar a ser "madres" de Cristo mediante su obediencia de fe: "Cumple tú la voluntad del Padre para que puedas ser madre de Cristo", Cfr. AMBROSIO. Obras de San Ambrosio. Tratado sobre el Evangelio de S. Lucas. Madrid: Biblioteca de Autores Cristianos, 1966, p. 533.
} 
Gentium, afirmando que "Dios nos ha dado a María como un principio que lo abarca todo, un punto de encuentro, por así decir, entre las distintas dimensiones de la iglesia". ${ }^{13}$ Advierte sobre el riesgo de minimalismo al acentuar la dimensión María-Iglesia y descuidar la figura esponsal de MaríaJesús. Y en cuanto a la relación recíproca entre María y los creyentes, teme que pudiera derivarse en una contemplación moralizante de su santidad e imitación de sus virtudes. ${ }^{14}$ La mariología que desarrolla es desde una perspectiva teodramática. Cuando alude al papel de Pedro, se refiere a la dimensión jerárquica e institucional que llama principio petrino.

El teólogo Joseph Ratzinger dice que "desde la humanización hubo ya Iglesia, ciertamente no institucional pues en María está personificada la Iglesia porque transmite el espíritu eclesial antes que esté organizada en Pedro. La maternidad de la Iglesia se hace clara y visible en el hecho y la manera de ser de María, la madre de Jesús. Ver a María es ver a la Iglesia. "La Iglesia es primero - y este "primero" es permanente - femenina, antes de que con el ministerio eclesial reciba el lado masculino complementario". ${ }^{15}$

Con un enfoque antropológico los teólogos Romano Guardini, Karl Rahner y Louis Bouyer, interpretaron el significado de María en la comprensión humana. Esta visión cuestionó las orientaciones unilaterales y triunfalistas de la mariología de los manuales. Es decir que se fueron incorporando en los estudios mariológicos, diversos modelos de pensamiento de la actual reflexión teológica: lingüística-analítica, socio-crítica y hermenéutica. ${ }^{16}$ Un ejemplo de ello es el ensayo del teólogo Müller escrito en $1980 .{ }^{17}$

En el Nuevo Diccionario de Mariología, ${ }^{18}$ se encuentran en sus páginas los aportes de los diversos mariólogos que profundizan en diversos campos. En la actualidad, ha surgido un interés por investigar la vida concreta de María,

${ }^{13}$ VON BALTHASAR, H. U. El complejo antirromano. Madrid: BAC, 1981, pp. 185-229, pp. $315 \mathrm{ss}$.

${ }^{14}$ Cfr. LEAHY, Breandan, op.cit.

${ }^{15}$ Cfr. RATZINGER, J.; VON BALTHASAR, H. U. María Iglesia naciente. $2^{\text {a }}$ edición. Madrid: ediciones Encuentro, 2006, pp. 109-110.

${ }^{16}$ Los teólogos destacados fueron Müller, Rahner, Dillenschneider, Laurentin y Gonzalo Gironés, entre otros.

${ }^{17}$ Cfr. MÜLLER, A. Discorso di fede sulla madre di Gesú. Un tentativo di mariología in propettiva contemporánea: Un tentativo di mariología in prospettiva contemporánea. Brescia, Queriniana, 1983, pp. 22-28.

${ }^{18}$ DE FIORES, S.; TOURÓN, M. E. S. Nuevo Diccionario de Mariología. Madrid: ediciones San Pablo, 2001. 
a través de las fuentes bíblicas descubriendo su historia en referencia a Jesús, su significado salvífico y lugar en la vida de la Iglesia.

Se ha despertado el interés por conocer sobre las apariciones y otras manifestaciones de la Virgen, que atraen multitudes, hechos que la Comisión de Doctrina de la Fe se encarga de analizar a través de las Conferencias Episcopales del país. Esta realidad es oportuna para que los mariólogos investiguen la fe vivida por los devotos y surjan aportes para la comprensión teológica de los mismos.

\section{Lineamientos magisterio latinoamericano y mariología}

Las Conferencias Episcopales Latinoamericanas aplican los documentos conciliares desde una hermenéutica latina y desde una opción por los pobres. Sus lineamientos guían la reflexión teológica de las Facultades de teología e Institutos teológicos donde se forman los presbíteros y laicos que buscan la fidelium quaerens intellectum para transmitir a las personas.

La referencia a María se encuentra en todas las Conferencias, desde Río de Janeiro a Aparecida (1955-2007) ${ }^{19}$ destacándose Puebla que profundiza en la mariología del Vaticano II y Aparecida que continúa esa misma línea. El documento de Río de Janeiro (1955), ${ }^{20}$ la cita en forma esporádica y sin relevancia teológica. Luego acontece un "silencio inexplicable" en el documento de Medellín (1968), ${ }^{21}$ que sólo alude a su protección.

El Documento de Puebla (DP) ${ }^{22}$ (1979), describe a María siguiendo la LG como "madre y modelo de la Iglesia" (DP 2.4), reconociendo en palabras de Pablo VI a la devoción mariana como un elemento "cualificador e intrínseco de la genuina piedad de la iglesia y del culto cristiano" (MC 56; DP 283). Confirma su maternidad divina y de Cristo histórico (DP 287), por eso es madre de la Iglesia. Siguiendo a LG 63, dice que es madre educadora de la fe, "pedagoga del Evangelio en América Latina." (DP 290; LG 63), y su presencia

${ }^{19}$ Cfr. DE FIORES, S. "María discípula y misionera en el camino pastoral de América Latina". En: PONTIFICIA COMISIÓN PARA AMÉRICA LATINA. Aparecida 2007. Luces para América Latina. Roma: librería Editrice Vaticana, 2008, pp. 65-76.

${ }^{20}$ Cfr. CELAM. I Conferencia General del Episcopado Latinoamericano, Rio de Janeiro. Montevideo: Ed. Paulinas, 1955.

${ }^{21}$ Cfr. CELAM. II Conferencia General del Episcopado Latinoamericano, Medellín. Montevideo: Ed. Paulinas, 1969.

22 Cfr. CELAM. III Conferencia General del Episcopado Latinoamericano, Puebla. Montevideo: Ed. Paulinas, 1979. 
"despierta el "corazón filial que duerme en todo hombre" (DP 295). Reconoce a la "Iglesia familia que tiene por madre a la Madre de Dios" (DP 285). Esboza su figura de mujer "creyente y discípula perfecta que se abre a la Palabra dejándose penetrar por su dinamismo" (DP 296). También se la califica como modelo de comunión, "entretejiendo una historia de amor con Cristo, íntima y santa verdaderamente única, que culmina en la gloria" (DP 292). En María y en Cristo, todos obtienen "los grandes rasgos de la verdadera imagen del hombre y la mujer" (DP 303). Y en la "hora de la nueva evangelización" y del nuevo Pentecostés, citando a Pablo VI pide "que María sea en este camino "Estrella de la Evangelización siempre renovada" (EN 8123; DP 303).

El documento de Santo Domingo (SD) ${ }^{24}$ (1992), presenta a María como modelo de evangelización de la cultura, pues "pertenece a la identidad cristiana de nuestros pueblos latinoamericanos", siendo "modelo de vida para los consagrados y apoyos seguro de su fidelidad" (SD 283 y 85). Es "protagonista de la historia por su libre cooperación, elevada a la máxima participación con Cristo." Y la "primera redimida y creyente", presente en la piedad popular (SD 15 y 53).

El Documento de Aparecida (DA) ${ }^{25}$ (2007), se realizó en un santuario mariano, ${ }^{26}$ en un ambiente de oración (cfr. DA 3), ubica la mariología dentro del precioso tesoro de la religiosidad popular que contiene una auténtica espiritualidad y mística. Continúa con las características esbozadas en el DP destacando que en su figura "vive su ser trinitario, siendo discípula misionera, formadora de discípulos misioneros" (DA 266). Educadora, formadora de la iglesia familia imprimiéndole "un sello mariano" por ser "Madre de la Iglesia (DA 267-268). Dentro del apartado 6.1.3, se destaca el lugar privilegiado que tiene la piedad mariana en la espiritualidad popular enriqueciendo la mariología popular, que es la manera como el pueblo vive su fe y amor a la Virgen María haciendo vida lo que ha recibido a través de la formación católica y el lugar que tiene María en el conjunto de la religión del pueblo. En el rostro de María "encuentran la ternura y el amor de Dios y ven reflejado el mensaje

${ }^{23}$ PABLO VI. Exhortación Apostólica Evangelii Nuntiandi. Montevideo: ediciones Paulianas, 1975.

${ }^{24}$ CELAM. IV Conferencia General del Episcopado Latinoamericano, Santo Domingo. Salto: Impresora Central, 1992.

${ }^{25}$ CELAM. V Conferencia General del Episcopado Latinoamericano, Aparecida. Bogotá: Ed. San Pablo, 2007.

${ }^{26}$ El Santuario nacional de Aparecida recibe cada semana aproximadamente unos 150.000 peregrinos, lo que produce un permanente flujo de personas por toda la basílica. 
esencial del Evangelio" (DA 265). Este amor a la Virgen "ha sido capaz de fundir las historias latinoamericanas diversas en una historia compartida" (DA 43). La gente manifiesta su fe a la madre de diversas maneras: novenas, peregrinaciones, rezo del rosario, promesas, sacrificios, ofrendas, entre otras.

En distintos momentos de la lucha cotidiana, muchos recurren a algún pequeño signo del amor de Dios: un crucifijo, un rosario, una vela que se enciende para acompañar a un hijo en su enfermedad, un Padrenuestro musitado entre lágrimas, una mirada entrañable a una imagen querida de María, una sonrisa dirigida al Cielo, en medio de una sencilla alegría. ${ }^{27}$

En esas expresiones descubrimos la presencia del Espíritu de Dios que es el que moviliza el corazón del creyente y el que propicia la "fides quaerens intellectum". En este sentido es importante valorar sin subestimar los gestos y las palabras de veneración, amor y alabanza dirigidos a la Virgen. Son manifestaciones de la fe de cada persona no menos que del colectivo social, que se transmiten a los demás y se socializan, por acciones de culto popular descritas en DA 261. La religión del pueblo contiene mucha riqueza teológica y cultural que requiere de una hermenéutica apropiada para su interpretación que tenga en cuenta el sentido común. Ese modo peculiar de pensar y vivir lo cristiano mariano es un aporte de nuestros pueblos a la búsqueda actual de la Iglesia. $^{28}$

Ante los problemas de América Latina y el Caribe, se apela a la figura de María que unifica y reconcilia a los pueblos por su "presencia materna indispensable y decisiva en la gestación de un pueblo de hijos y hermanos, discípulos y misioneros de su Hijo" (cfr. DA 524). Es modelo de fe, "la más perfecta discípula y el primer miembro de la comunidad de los creyentes en Cristo". "Mujer libre y fuerte, conscientemente orientada al seguimiento de Cristo" (DA 266 y 269). "Espléndida imagen de configuración según el proyecto trinitario que se realiza en Cristo" (DA 141). "Seguidora más radical de Cristo y su magisterio", por lo cual Benedicto XVI, invita a "permanecer en la escuela de María" (DA 270). Siendo discípula entre los discípulos, colabora

\footnotetext{
${ }^{27}$ DA 261.

${ }^{28}$ Cfr. GALILEA, S. “Análisis empírico de la religiosidad latinoamericana”. En: BÜNTIG, A. et al. Catolicismo

popular. Quito: IPLA, 1979. GALILEA, S. Religiosidad popular y pastoral. Madrid: Ediciones Cristiandad, 1979, p.327; RIBEIRO DE OLIVEIRA, P. A. O catolicismo do povo. Cadernos de Teologia e Pastoral, $n^{\circ}$ 8. Petrópolis: Vozes, 1978.
} 
en la recuperación de la "dignidad de la mujer y su valor en la Iglesia". Se compromete con "su realidad con voz profética" (DA 451) como en el Magnificat. Cuando se afronta el problema de la dignidad y participación de las mujeres en la vida de la comunidad, es referencia para "escuchar el clamor silenciado de las mujeres sometidas a la exclusión y a la violencia" (DA 454). Al final del documento los obispos piden su "compañía siempre cercana, llena de compasión y de ternura" y que ella "nos enseñe a salir de nosotros mismos en camino de sacrificio, amor y servicio" (DA 453).

\section{Mariología latinoamericana}

Entre los teólogos y teólogas latinoamericanas que han ahondado la mariología desde la teología de la liberación e influenciados por la teología europea encontramos a Leonardo Boff, ${ }^{29}$ que aborda la figura de María-mujer, persona histórica y objeto de fe. Es un primer ensayo mariológico adaptado a la realidad del momento, recuperando los datos de la tradición eclesial y buscando la integración de la mariología en la teología en el contexto bíblicosalvífico-cultural. Las múltiples interpelaciones que enfrenta por insertarse lleva a que se integre en la teología y que no sea un tratado autónomo. ${ }^{30} \mathrm{La}$ hipótesis que plantea sobre una relación hipostática entre María y el Espíritu Santo, fue muy discutida.

El teólogo González Dorado, ${ }^{31}$ estudió la teología mariana autóctona subyacente en la piedad popular, siendo pionero en este campo. Describe el significado de la mariología popular, el método para su investigación y aporta elementos para la comprensión de la fe mariana popular.

Entre los teólogos que han realizado estudios de la religiosidad popular describiendo la fe mariana se encuentran: Diego Irarrázaval (Chile); Carlos Mesters (Brasil); Lucio Gera, Rafael Tello, Carlos María Galli, argentinos que describen las manifestaciones de fe popular mariana desde la teología

\footnotetext{
${ }^{29}$ BOFF, L. El Rostro materno de Dios: ensayo interdisciplinar sobre lo femenino y sus formas religiosas. San Pablo: Ediciones Paulinas, 1979.

${ }^{30}$ Teólogos como A. Müller y J. Ratzinger apelan a su inclusión en la teología para evitar el aislamiento y la pérdida de límites. Otros como J. Galot y M. Llamera, buscan un tratado distinto de mariología para superar estudios fragmentarios con una síntesis doctrinal completa y orgánica.

${ }^{31}$ GONZÁLEZ DORADO, A. De María conquistadora a María liberadora. Madrid: Editorial Sal Térrea, 1988.
} 
del pueblo. Clodovis Boff ${ }^{32}$ ofrece un intenso trabajo de investigación sobre Mariología social, con un rico aporte bibliográfico. Entre las muchas investigaciones realizadas por teólogas se destacan: Ivonne Gevara y María Clara Bingemer, ${ }^{33}$ con su obra pionera desde la antropología y la interpretación de los dogmas marianos en la vida del pueblo. Los ensayos de mariología en la óptica latinoamericana y caribeña de Lina Boff. ${ }^{34}$ Una relectura de los dogmas ahondando en la figura de María desde la fe de la Iglesia de María Clara Temporelli. ${ }^{35} \mathrm{La}$ investigación sobre mariología popular Latinoamericana de mi autoría. ${ }^{36}$

Sobresalen también las publicaciones del CELAM sobre Mariología. Tanto desde la perspectiva del Magisterio episcopal continental, como de los santuarios marianos y del encuentro continental de pastoral mariana y congreso teológico pastoral-mariano (2007). ${ }^{37}$ Sus investigaciones contribuyen para el estudio teórico y pastoral de la mariología.

En la teología latina en EEUU, es innumerable el aporte en libros y revistas de los estudios sobre la Virgen de Guadalupe del Centro de Estudios Guadalupanos de Virgilio Elizondo, desarrollando el tema del mestizaje. El aporte de la teóloga Elizabeth Johnson, ${ }^{38}$ contribuyó presentando una teología mariana liberadora. A través de una hermenéutica femenina de las Escrituras.

\section{Papa Francisco y su magisterio mariano}

¿Qué aporte ofrece el papa Francisco a la mariología? Sigue la línea teológica del Vaticano II y de los documentos eclesiales latinoamericanos especialmente el de Aparecida porque fue el Presidente de la Comisión de

\footnotetext{
${ }^{32}$ BOFF, C. Mariologia social. O significado da Virgem para a Sociedade. Sao Paulo: Edições Paulus, 2006.

${ }^{33}$ GEBARA, I.; BINGEMER, M. C. María, mujer profética. Ensayo teológico a partir de la mujer y de América Latina. San Pablo: Ediciones Paulinas, 1988.

${ }^{34} \mathrm{BOFF}$, L. María na vida do povo. Ensaios de mariologia na ótica latino-americana e caribenha. Säo Paulo: Paulus, 2001.

35 TEMPORELLI, M. C. María, mujer de Dios y de los pobres. Relectura de los dogmas marianos. Buenos Aires: Editorial San Pablo, 2008.

${ }^{36}$ SILVEIRA, M. P. Mariología popular Latinoamericana. Fisonomía de la Mariología popular venezolana, Caracas: UCAB-Arquidiócesis de Mérida, 2013.

${ }^{37}$ CELAM. María, Madre de discípulos. Encuentro continental de pastoral mariana y congreso teológico pastoral-mariano. Bogotá: colección Quinta Conferencia, 2007.

38 JOHNSON, E. A. Verdadera hermana nuestra. Teología de María en la comunión de los santos. Barcelona: editorial Herder, 2005.
} 
redacción del Documento final de Aparecida siendo Cardenal. En su magisterio se observa la influencia de la teología del pueblo desarrollada en Argentina. ${ }^{39}$ La figura de María-Iglesia la encontramos en diversas homilías:

Para nosotros, María se convierte en un icono de cómo la Iglesia debe extender el perdón a cuantos lo piden. La Madre del perdón enseña a la Iglesia que el perdón ofrecido en el Gólgota no conoce límites. No lo puede detener la ley con sus argucias, ni los saberes de este mundo con sus disquisiciones. El perdón de la Iglesia debe tener la misma amplitud que el de Jesús en la Cruz, y el de María a sus pies. No hay alternativa ${ }^{40}$

En la homilía de la fiesta de la Asunción expresa:

El Concilio Vaticano II, al final de la Constitución sobre la Iglesia, nos ha dejado una bellísima meditación sobre María Santísima (...). La figura de la mujer, que representa a la Iglesia, aparece por una parte gloriosa, triunfante, y por otra con dolores. Así es en efecto la Iglesia: si en el Cielo ya participa de la gloria de su Señor, en la historia vive continuamente las pruebas y desafíos que comporta el conflicto entre Dios y el maligno, el enemigo de siempre (...). ${ }^{41}$

En la Exhortación Apostólica Evagengelii Gaudium (EG) ${ }^{42}$ describe a la iglesia Pueblo de Dios encarnada en cada uno de los pueblos de la tierra que tiene su propia cultura desplegando la belleza de un rostro pluriforme. ${ }^{43}$ Es una madre de corazón abierto y casa siempre abierta para todos. ${ }^{44}$ Exhorta a los fieles a la imperiosa necesidad de evangelizar las culturas donde se encuentra la piedad popular o espiritualidad popular encarnada en la piedad de los sencillos, mística popular. Legitima el acto de fe popular donde se destaca la mariología popular.

\footnotetext{
${ }^{39}$ Sigue la teología de Rafael Tello, Lucio Gera, Juan Carlos Scannone.

${ }^{40}$ FRANCISO. "Homilía Solemnidad de Santa María, Madre de Dios". Vatican, Roma, 1 de enero de 2015. Disponible en: <http://w2.vatican.va/content/francesco/es/homilies/2016/documents/papa-francesco_20160101_omelia-giornata-mondiale-pace.html>. Consulta el 17 de abril de 2017.

${ }^{41}$ Ídem, "Homilía solemnidad de la Asunción de la Virgen María." Vatican, Roma, 15 de agosto 2013. Disponible en: <http://w2.vatican.va/content/francesco/es/homilies/2013/documents/ papa-francesco_20130815_omelia-assunzione.html>. Consulta el 18 de abril de 2017.

${ }^{42}$ FRANCISCO. Exhortación Apostólica Evangelii Gaudium. Roma: Tipografía Vaticana, 2013.

${ }^{43}$ Cfr. EG 116.

${ }^{44}$ Cfr. EG, apartado V Una madre de corazón abierto.
} 
El caminar juntos hacia los santuarios y el participar en otras manifestaciones de la piedad popular, también llevando a los hijos o invitando a otros, es en sí mismo un gesto evangelizador. ¡No coartemos ni pretendamos controlar esa fuerza misionera! ${ }^{45}$

Implícitamente en esta expresión se menciona el papel de la mujer en la piedad popular que en el siguiente numeral destaca:

Sólo desde la connaturalidad afectiva que da el amor podemos apreciar la vida teologal presente en la piedad de los pueblos cristianos, especialmente en sus pobres. Pienso en la fe firme de esas madres al pie del lecho del hijo enfermo que se aferran a un rosario aunque no sepan hilvanar las proposiciones del Credo, o en tanta carga de esperanza derramada en una vela que se enciende en un humilde hogar para pedir ayuda a María, o en esas miradas de amor entrañable al Cristo crucificado. Quien ama al santo Pueblo fiel de Dios no puede ver estas acciones sólo como una búsqueda natural de la divinidad. Son la manifestación de una vida teologal animada por la acción del Espíritu Santo que ha sido derramado en nuestros corazones (cf. $R m$ 5,5). ${ }^{46}$

La fe popular contiene la presencia silenciosa del Espíritu el sensus fidei que le otorga a los cristianos una cierta familiaridad con las realidades divinas y una sabiduría para captarlas intuitivamente, aunque no encuentren palabras para explicar su fe. ${ }^{47}$ Francisco invita a prestar atención y no ser indiferentes ante las múltiples expresiones de piedad popular ya que son un lugar teológico que hay que saber interpretar en la nueva evangelización. ${ }^{48}$ En la figura de María, santuario del Espíritu Santo, madre de todos, el Papa concluye la Exhortación reconociendo que "hay un estilo mariano en la actividad evangelizadora de la Iglesia". Porque "cada vez que miramos a María volvemos a creer en lo revolucionario de la ternura y del cariño. En ella vemos que la humildad y la ternura no son virtudes de los débiles sino de los fuertes, que no necesitan maltratar a otros para sentirse importantes". ${ }^{49}$ Podemos decir que la actividad evangelizadora de la Virgen que atrae por convicción como se observa en los

\footnotetext{
${ }^{45}$ Cfr. EG 124.

${ }^{46}$ Cfr. EG 125.

${ }^{47}$ Cfr. EG 119.

${ }^{48}$ Cfr. EG 126.

${ }^{49}$ Cfr. EG 288.
} 
santuarios marianos, nos lleva a observar en silencio la acción de Dios que siempre supera nuestras expectativas y planes organizados para ponernos en movimiento y continuar el camino de la fe.

\section{Reflexión actual Mariología Magisterial y mariología popular}

Al señalar un brevísimo recorrido de la influencia teológica del Vaticano II en Europa y en AL a través del magisterio pontificio las Conferencias Episcopales y de la reflexión teológica, podemos decir que el lugar que ocupa María es en referencia a Cristo y a la Iglesia. La relación María-Cristo-Iglesia se ha mantenido constante siguiendo los lineamientos de la LG. El avance de los estudios bíblicos, con la ayuda de las ciencias entre ellas la antropología, la psicología ${ }^{50}$ su descripción de lo femenino por la influencia de teólogas que han incursionado en ese campo, su referencia a Jesús, han hecho posible que la imagen de María sea más real y no tan especial como inaccesible.

Ante el planteamiento del Papa Francisco al inicio de este artículo invitando a elaborar la teología en las fronteras y no en los despachos, describiré el trabajo de investigación que he realizado, acercándome al lugar teológico, en este caso la fe popular mariana, descubriendo la teología que contiene. Analicé el contenido de 14 Cuadernos de intenciones recogidos en la Peregrinación Misionera: La Visita de Jesucristo y la Virgen de Guadalupe a los Pueblos de América Latina y El Caribe, $(1992-2000)^{51}$ en su visita a Venezuela. ${ }^{52}$ Examiné las intenciones escritas durante la visita a los santuarios

\footnotetext{
${ }^{50}$ NAVARRO PUERTO, M. María, la Mujer. Ensayo psicológico Bíblico. Madrid: Publicaciones claretianas, 1987.

${ }^{51}$ Cf. SILVEIRA, M. P. Mariología popular Latinoamericana, 86. La idea surgió de un grupo de sacerdotes y laicos argentinos, respondiendo a la llamada de Juan Pablo II a una evangelización nueva en su impulso misionero, en sus métodos y expresión. El camino se inauguró el 12 de diciembre de 1992 en la Basílica de Ntra. Señora de Guadalupe en México y concluyó en Luján, Argentina, el 12 de diciembre del 2000. En su primera etapa recorrió diez países de América Central, el norte de Colombia y la República Dominicana. Duró un año y medio y se recorrieron $7400 \mathrm{~km}$. El segundo tramo comenzó en diciembre de 1994, recorriendo Venezuela, Colombia, Ecuador, Perú y Bolivia. Esta vez se hicieron $7.100 \mathrm{~km}$ de caminata. La tercera etapa partió en abril de 1997 y abarcó Brasil y Uruguay con un total de $3.577 \mathrm{~km}$. La cuarta y última etapa del camino partió en diciembre de 1998 desde Mendoza y terminó en diciembre del año 2000 - abarcando gran parte de Argentina y Chile - en la Basílica de Ntra. Sra. de Luján, recorriendo 24.000 kilómetros en total.

${ }^{52}$ La Peregrinación Misionera visitó Venezuela desde el 28 de diciembre de 1994 al 28 de marzo de 1995. La misma se la ubica en la segunda etapa del recorrido desde México a Luján. Se recogieron un total 85 Cuadernos de intenciones que contienen las expresiones de fe de
} 
de La Divina Pastora en Santa Rosa, Barquisimeto, de Nuestra Señora del Rosario de la Chiquinquirá en Maracaibo y de Nuestra Señora de Coromoto en Guanare. A esta fuente se incluyeron 279 entrevistas junto con las Observaciones realizadas en las fiestas de las mismas advocaciones en los años 2008 y 2009. En Venezuela hay una "matriz" mariana que forma parte de la cultura popular, pues sucedió la segunda aparición histórica de la Virgen de Coromoto reconocida por la Iglesia. Se venera porque la gente ve en su pobreza, sencillez y sufrimiento reflejada su vida cotidiana como en un espejo. Ella por ser madre comprende sus sufrimientos y su vida, es parte de sus luchas. En los Cuadernos de Intenciones, las personas "le cuentan todo" abren con confianza su vida sin tapujos buscando una solución a sus situaciones. ${ }^{53}$ Para el abordaje de este complejo mundo de la religiosidad popular mariana, conté con el apoyo interdisciplinar de otras ciencias tales como la historia, la sociología y la antropología cultural.

Los resultados del estudio hecho siguiendo la racionalidad del método teológico ver-juzgar-actuar, certifican que en el sensus fidelium de la religiosidad popular, se encuentra el amor a María-Madre, donde se puede apreciar la relación entre la mariología y la eclesiología. Es decir que para los devotos y devotas, amar a María y estar junto a ella en la celebración de su fiesta patronal, significa ser Iglesia y estar en comunión con los demás creyentes de la familia eclesial. Se descubre así, el concepto popular de participación y la fisonomía del rostro de la Iglesia popular mariana conformada por una mayoría de mujeres.

También confirma la profunda unión entre la mariología y la cristología en el sensus fidelium de los creyentes, ya que amar a la Madre conlleva a amar al Hijo. Se destaca la figura popular de María, "Evangelio Vivido," que es conocida por la meditación del Avemaría y los misterios del Santo Rosario donde el pueblo se nutre del contenido teológico del Evangelio, comprende los dogmas marianos y la figura de María Liberadora. Si bien esta fe se transmite en la cultura creando un sustrato católico, se evidencia la necesidad

los venezolanos en los diversos lugares donde pasó, tales como: Caracas, Turmero, Valencia, Chivacoa, Yaritagua, Barquisimeto, Maracaibo, Acarigua, Guanare, Mérida, Barinas, Campo Alegre, Acarigua, entro otras.

${ }^{53}$ Silveira, M. P. op.cit. La investigación estudió 14 Cuadernos de Intenciones escritos por los devotos en la Peregrinación Misionera (1992-2000) desde México a Argentina con la imagen de la Virgen de Guadalupe y el Cristo de las Esquipulas. También se realizaron encuestas y observaciones en las fiestas de las Nuestra Sra. de Coromoto, La Chinita y La Divina Pastora en Venezuela. 
de continuar catequizando entregado la Palabra de Dios a través de diversos medios como la lectura orante, para que su figura y la de Jesús sea conocida y amada sin desviaciones.

La liturgia popular simbólica se manifiesta en las ricas y diversas expresiones de fe mariana tales como las peregrinaciones a los santuarios, los gestos corporales, las oraciones, las promesas, entre otras. En las mismas se observa la relación personal-multitudinaria con María en las fiestas patronales que conforman la cultura popular descubriendo sus fortalezas y áreas de oportunidad siendo necesaria una nueva evangelización inculturada.

Hay aciertos que permanecen desde la primera evangelización que es la transmisión de la fe a través de la Palabra y la imagen, de allí surgen las devociones. Las personas aprendieron a rezar en su propio idioma, se familiarizaron con la Virgen, en el rezo del Rosario encontraron todas las oraciones para rezar en la iglesia doméstica de su hogar. Cuando iban a la Misa en Latin, significaba participar en un acto religioso del "sacerdote" que estaba de espalda al pueblo y orando en su propio idioma. El pueblo que no sabia latin, oraba en su lengua el Padre Nuestro, el Avemaría y en el Rosario encontraba la manera de unirse a la vida de Jesús a través de María Las encuestas de la investigación, revelan el rostro popular de la "única" Virgen María, la Madre de Dios, "Milagrosa," junto a muchos otros vocativos que creativamente el lenguaje popular posee para referirse a María. Profundiza en la manera de orar desde el corazón, con amor y fe, con gestos y palabras. Describe la antropología subyacente en las devociones y destaca el lugar de la mujer-madre, comunicadora de la fe en la familia y en la sociedad. Da algunas pistas para la comprensión de lo materno-filial, la "madredad," en el contexto venezolano.

Profundiza en la espiritualidad trinitaria mariana fruto del encuentro con María, ícono de la Trinidad. Enfatiza su influencia en la vida familiar, personal, social y eclesial, así como en la cultura y en las posibles repercusiones políticas y económicas.

Se puede observar en este aporte de mariología popular latinoamericana, la comprensión por parte de la gente de la mariología magisterial predicada por la Iglesia, "sin maquillaje, ni adornos", como dice el Papa Francisco. Esta realidad nos interpela para conocerla y acompañarla ya que la mariología popular muestra una imagen plástica, de una Iglesia mariana peregrina, en movimiento, que forma una familia en un clima de fiesta, de hermandad, de júbilo. Una Iglesia al "aire libre" en contacto con la naturaleza, un "cuerpo en 
movimiento", tanto simbólico como en la realidad. Es la imagen que se puede dibujar al ver una multitud de personas juntas, caminando, entrando y saliendo del santuario, con diversas expresiones de dolor, júbilo, cansancio y alegría por llegar a la meta y estar junto a la Madre. Es preciso un permanente acercamiento a la fe de la gente sencilla, para ir conociendo con una hermenéutica adecuada su contenido y así acompañar los procesos teniendo en cuenta los signos de los tiempos. En el permanente intercambio entre la doctrina y la fe vivida que es la comprensión de la Palabra predicada, es posible conocer su estado actual.

\section{Conclusión}

Los lineamientos de estos últimos años perfilan un rostro de Maríamujer-madre de Jesús- Iglesia que vive en los sencillos. Los misterios que se han profundizado desde el siglo XX hasta la actualidad son el misterio de la encarnación y de la asunción. Se ubica a la mujer que vivió en un lugar y tiempo determinado y su misión como madre de Dios que corporalmente nos trasciende al subir junto a su Hijo, misterio que describe la LG 59. El lugar teológico de la comunión de los santos, ofrece a María la condición de aparecerse, de hacerse visible porque sigue cuidando a sus hijos e hijas.

El misterio de la encarnación se entiende una Iglesia que peregrina, que busca ser familia, crear fraternidad, denunciar las injusticias con las características de María, una Iglesia mariana que crece por atracción y que no solo se queda en lo institucional y burocrático que envejece su rostro. Uno de los desafíos que encuentra es la proliferación de manifestaciones como las apariciones, que despiertan o sacuden la fe dormida mas allá de lo institucional. Dios a través de la Virgen sigue actuando en la historia y hay que sintonizar con El descubriendo su presencia y su acción en el sensum fidelium popular.

La Mariología Magisterial es la columna vertebral del Cuerpo que es la Iglesia, a través de las definiciones dogmáticas que como dice Ratzinger, no son muros, sino ventanas para comprender el misterio, son las que sostienen al cuerpo. La mariología popular es el actuar del cuerpo, las acciones que realiza en la vida concreta, por lo cual son múltiples variadas, coloridas, simbólicas, creativas, espontáneas. Necesitan estar unidas al cuerpo, sin él no tienen sentido y ambas se complementan. Las palabras pronunciadas en Puebla confirman la importancia de una adecuada hermenéutica:

Si la Iglesia no reinterpreta la religión del pueblo latinoamericano, se 
producirá un vacío que lo ocuparán las sectas, los mesianismos políticos secularizados, el consumismo que produce hastío y la indiferencia o el pansexualismo pagano. Nuevamente la Iglesia se enfrenta con el problema: lo que no asume en Cristo, no es redimido y se constituye en un ídolo nuevo con malicia vieja. ${ }^{54}$

Si la teología la seguimos elaborando desde los despachos, se transmitirá una fe que no tiene asidero en el tejido vivo de la religiosidad popular que nos revitaliza y nos cuestiona. Tener las herramientas para conocerla y enseñarla es una tarea que es importante realizar en las Facultades de Teología.

En Latinoamérica estamos en un momento propicio impulsado por el magisterio del Papa Francisco para valorar la riqueza del aporte de la teología del pueblo a la humanidad, especialmente la mariología popular. Quedan muchos desafíos por abordar, como la necesidad de seguir investigando y de enseñar la metodología y el lenguaje para comprender la fe popular. Hay mucha fe vivida y poca investigación que impulsa a conocer desde dentro a la fe mariana sin teorizar ni subestimar o sobrevalorarla. Para que ocupe su lugar en la vida eclesial sobre todo en la evangelización.

Concluyo con parte de la oración del Papa Francisco:

María, la mujer de la escucha, de la decisión, de la acción.

María, mujer de la escucha, haz que se abran nuestros oídos; que sepamos escuchar la Palabra de tu Hijo Jesús entre las miles de palabras de este mundo; haz que sepamos escuchar la realidad en la que vivimos, a cada persona que encontramos, especialmente a quien es pobre, necesitado, tiene dificultades.

María, mujer de la decisión, ilumina nuestra mente y nuestro corazón, para que sepamos obedecer a la Palabra de tu Hijo Jesús sin vacilaciones; danos la valentía de la decisión, de no dejarnos arrastrar para que otros orienten nuestra vida.

María, mujer de la acción, haz que nuestras manos y nuestros pies se muevan «deprisa» hacia los demás, para llevar la caridad y el amor de tu Hijo Jesús, para llevar, como tú, la luz del Evangelio al mundo. Amén. ${ }^{55}$

\footnotetext{
${ }^{54}$ SILVEIRA, M. P. Mariología popular latinoamericana, 469.

${ }^{55}$ FRANCISCO. "Rezo del santo rosario como conclusión del mes mariano". Viernes 31 de mayo 2013. Disponible en: <http://w2.vatican.va/content/francesco/es/speeches/2013/may/ documents/papa-francesco_20130531_conclusione-mese-mariano.html $>$. Consulta el 20 de abril de 2017.
} 


\section{Referencias bibliográficas}

AMBROSIO. Obras de San Ambrosio. Tratado sobre el Evangelio de S. Lucas. Madrid: Biblioteca de Autores Cristianos, 1966.

BENEDICTO XVI. "Discurso de apertura XXIII Congreso Mariológico Mariano Internacional." Gaudiumpress, Roma, 10 de octubre de 2012. Disponible en: <http://es.gaudiumpress.org/content/40129-El-ConcilioVaticano-II-representa-en-la-mariologia-el-punto-de-equilibrio-entrela-racionalidad-teologica-y-la-afectividad-creyente--observa-el-Papa> . Consultado 13 de abril 2017.

BOFF, C. Mariologia social. O significado da Virgem para a Sociedade. Sao Paulo: Edições Paulus, 2006.

BOFF, L. El Rostro materno de Dios: ensayo interdisciplinar sobre lo femenino y sus formas religiosas. San Pablo: Ediciones Paulinas, 1979.

BOFF, L. María na vida do povo. Ensaios de mariologia na ótica latinoamericana e caribenha. Säo Paulo: Paulus, 2001.

CELAM. I Conferencia General del Episcopado Latinoamericano, Rio de Janeiro. Montevideo: Ed. Paulinas, 1955.

CELAM. II Conferencia General del Episcopado Latinoamericano, Medellín. Montevideo: Ed. Paulinas, 1969.

CELAM. III Conferencia General del Episcopado Latinoamericano, Puebla. Montevideo: Ed. Paulinas, 1979.

CELAM. IV Conferencia General del Episcopado Latinoamericano, Santo Domingo. Salto: Impresora Central, 1992.

CELAM. VConferencia General del Episcopado Latinoamericano, Aparecida. Bogotá: Ed. San Pablo, 2007.

CELAM. María, Madre de discípulos. Encuentro continental de Pastoral mariana y Congreso Teológico Pastoral-mariano. Bogotá: Colección Quinta Conferencia, 2007.

DE FIORES, S.; TOURÓN, M. E. S. Nuevo Diccionario de Mariología. Madrid: ediciones San Pablo, 2001.

DE FIORES, S. "María discípula y misionera en el camino pastoral de América Latina". En: PONTIFICIA COMISIÓN PARA AMÉRICA 
LATINA. Aparecida 2007. Luces para América Latina. Roma: librería Editrice Vaticana 2008, pp. 65-76.

DE LUBAC, H. Meditación sobre la Iglesia. Pamplona: Desclée de Brouwer, 1959.

DELAHAYE, K. Ecclesia Mater. Paris: Les Éditions du Cerf, 1964.

FRANCISCO. "Carta al Cardenal Mario Aurelio Poli, Arzobispo de Buenos Aires y Gran Canciller de la Universidad Católica Argentina (UCA) en ocasión de los 100 años de la Facultad de Teología." Aciprensa, Roma, 3 de marzo de 2015. Disponible en: <https:// www.aciprensa.com/noticias/no-se-conformen-con-una-teologia-dedespacho-pide-papa-francisco-a-la-uca-13143/>. Consulta el 5 de abril 2017.

FRANCISCO. Exhortación Apostólica Evangelii Gaudium. Roma: Tipografía Vaticana, 2013.

FRANCISCO. "Rezo del santo rosario como conclusión del mes mariano". Viernes 31 de mayo 2013. Disponible en: <http://w2.vatican. $\mathrm{va} /$ content/francesco/es/speeches/2013/may/documents/papafrancesco_20130531_conclusione-mese-mariano.html $>$. Consulta $20 \mathrm{de}$ abril de 2017.

FRANCISCO. "Homilía Solemnidad de Santa María, Madre de Dios". Vatican, Roma, 1 de enero de 2015. Disponible en: <http://w2.vatican.va/content/ francesco/es/homilies/2016/documents/papa-francesco_20160101_ omelia-giornata-mondiale-pace.html>. Consulta el 17 de abril de 2017.

FRANCISCO. "Homilía Solemnidad de la Asunción de la Virgen María." Vatican, Roma, 15 de agosto 2013. Disponible en: <http:// w2.vatican.va/content/francesco/es/homilies/2013/documents/papafrancesco_20130815_omelia-assunzione.html>. Consulta el 18 de abril de 2017.

GALILEA, S. "Análisis empírico de la religiosidad latinoamericana". En: BÜNTIG, A. et al. Catolicismo popular. Quito: IPLA, 1979.

GALILEA, S. Religiosidad populary pastoral. Madrid: Ediciones Cristiandad, 1979.

GEBARA, I.; BINGEMER, M. C. María, mujer profética. Ensayo teológico a partir de la mujer y de América Latina. San Pablo: Ediciones Paulinas, 
1988.

GONZÁLEZ DORADO, A. De María conquistadora a María liberadora. Madrid: Editorial Sal Térrea, 1988.

JUAN PABLO II. “Carta apostólica Mulieris Dignitatem”. Vatican, Roma, 30 de septiembre de 1988. Disponible en: <https://w2.vatican.va/content/johnpaul-ii/es/apost_letters/1988/documents/hf_jp-ii_apl_19880815_mulierisdignitatem.html>. Consulta el 13 de abril de 2017.

JUAN PABLO II. Exhortación Apostólica Redemptoris Mater. Bogotá: Ediciones Paulinas, 1988.

LEAHY, B. El principio mariano en la eclesiología de Hans Urs Von Balthasar. Madrid: Ciudad Nueva, 2002.

MÜLLER, A. Discorso di fede sulla madre di Gesú. Un tentativo di mariología in propettiva contemporánea: Un tentativo di mariologia in prospettiva contemporánea. Brescia: Queriniana, 1983, pp. 22-28.

ORIGENES. Homilías sobre el cantar de los cantares. Introducción, traducción y notas de Samuel Fernández Eyzaguirre. Madrid: Ciudad Nueva, 2000.

PABLO VI. Exhortación Apostólica Marialis Cultus. Roma: Tipografía Vaticana, 1974.

PABLO VI. Exhortación Apostólica Evangelii Nuntiandi. Montevideo: ediciones Paulianas, 1975.

PLUMPE, J. Mater Ecclesia. Washington: Catholic University of America Press, 1943.

RATZINGER, J.; VON BALTHASAR, Hans Urs. María Iglesia naciente. $2^{\mathrm{a}}$ edición. Madrid: ediciones Encuentro, 2006.

RIBEIRO DE OLIVEIRA, P. A. O catolicismo do povo. Cadernos de Teologia e Pastoral, $n^{\circ} 8$. Petrópolis: Vozes, 1978.

SILVEIRA, M. P. Mariología popular Latinoamericana. Fisonomía de la Mariología popular venezolana. Caracas: UCAB-Arquidiócesis de Mérida, 2013.

VATICANO II. "Dei Verbum”. In: Documentos Conciliares. Buenos Aires: Ediciones Paulinas, 1988, pp. 97-109. 
VATICANO II. "Lumen Gentium". In: Documentos Conciliares. Buenos Aires: Ediciones Paulinas, 1988, pp. 80-90.

VON BALTHASAR, H. U. El complejo antirromano. Madrid: La Bac, 1981.

VON BALTHASAR, H. U. Teoldramática II. Madrid: Encuentro, 1992.

TEMPORELLI, M. C. María, mujer de Dios y de los pobres. Relectura de los dogmas marianos. Buenos Aires: Editorial San Pablo, 2008.

María del Pilar Silveira

Doctora en Teología por la Pontificia Universidad Javeriana (Bogotá)

Profesor Aggiunto Universitá Pontificia Salesiana, sede Iter-Ucab

Caracas / Venezuela

E-mail: mpilarsilveira@gmail.com 